\title{
Invasive group B Streptococcus among non-pregnant adults in Brussels-Capital Region, 2005-2019
}

\author{
Elena Graux ${ }^{1} \cdot$ Maya Hites $^{2}$ (D) $\cdot$ Delphine Martiny ${ }^{3,4} \cdot$ Evelyne Maillart $^{5} \cdot$ Marc Delforge $^{1} \cdot{\text { Pierrette } \text { Melin }^{6} \text { (i) }}^{\text {. }}$ \\ Nicolas Dauby ${ }^{1,7,8}$
}

Received: 3 July 2020 / Accepted: 10 September 2020 / Published online: 17 September 2020

(C) Springer-Verlag GmbH Germany, part of Springer Nature 2020

\begin{abstract}
To assess the incidence, clinical, microbiological features and outcome of invasive Streptococcus agalactiae (GBS) infections in non-pregnant adults in three tertiary hospitals of the Brussels-Capital Region. All bacterial cultures positive for GBS, from 2005 to 2019 from 3 hospitals of the Brussels-Capital Region, were extracted, and only cases of invasive diseases were included. Medical files were retrospectively retrieved for risk factors, clinical manifestations and outcome and also antibiotic-susceptibility testing and GBS serotypes. Incidence rates were calculated based on the hospitals catchment populations. A total of 337 cases of GBS-invasive infections were included. The incidence of invasive GBS for the 3 hospitals increased from 3.7 to 8.2 cases per 100.000 inhabitants between 2009 and $2018(p=0.04)$. The most frequently identified risk factors were diabetes $(36.8 \%)$, obesity (35.0\%), cancer (21.7\%), renal disease (20.8\%), and advanced age ( $\geq 65$ years; $47.2 \%)$. Isolated bacteremia (22\%), osteoarticular infection (21.4\%), abscesses (13.9\%), and skin and soft tissue infections (18.4\%) were the most frequent manifestations. Intensive care unit admission was required in $21.7 \%$ and overall mortality was $9.4 \%$. All strains remained susceptible to penicillin over the years. Up to $20 \%$ of strains were resistant to clindamycin. Serotypes Ia, Ib, II, III, IV, and V represented $96.8 \%$ of the available serotypes (60/62). As reported in several countries, invasive GBS disease in non-pregnant adults represents an increasing burden, particularly among diabetic, obese, and elderly patients. Almost all serotypes identified are included in the upcoming hexavalent GBS conjugate vaccine.
\end{abstract}

Keywords Group B Streptococcus · Non-pregnant adults · Invasive infections · Incidence $\cdot$ Serotypes · Vaccine $\cdot$ Obesity · Diabetes

Electronic supplementary material The online version of this article (https://doi.org/10.1007/s10096-020-04041-0) contains supplementary material, which is available to authorized users.

Nicolas Dauby

Nicolas_DAUBY@stpierre-bru.be

1 Department of Infectious Diseases, Centre Hospitalier Universitaire Saint-Pierre, Université Libre de Bruxelles (ULB), 322, rue Haute, 1000 Bruxelles, Belgium

2 Clinic of Infectious Diseases, Cliniques Universitaires de Bruxelles Erasme, Bruxelles, Belgium

3 Department of Microbiology, Laboratoire des Hôpitaux Universitaires de Bruxelles - Universitaire Laboratorium Brussel (LHUB-ULB), Bruxelles, Belgium
4 Faculté de Médecine et Pharmacie, Université de Mons (UMONS), Mons, Belgium

5 Department of Infectious Diseases, CHU Brugmann, Bruxelles, Belgium

6 Clinical Microbiology, CHU Liège, National Reference Centre Streptococcus agalactiae, CIRM, Liège, Belgium

7 Centre for Environmental Health and Occupational Health, School of Public Health, Université Libre de Bruxelles (ULB), Brussels, Belgium

8 Institute for Medical Immunology, Université Libre de Bruxelles (ULB), Brussels, Belgium 


\section{Introduction}

Streptococcus agalactiae or group B Streptococcus (GBS) is a commensal bacterium of the digestive tract present in 15-35\% of men and women of all ages. GBS can secondarily colonize the urinary and genital tracts [1-3].

GBS is a major and well-known cause of severe infections in pregnant women and newborns [1,2]. Systematic screening for maternal colonization between the 35th and 37th weeks of pregnancy, followed by antibiotic prophylaxis administered during labor in case of testing positive, significantly reduces the incidence of perinatal GBS disease [4].

The first sporadic case reports of GBS infection in nonpregnant adults were described in the 1940s [5]. Several epidemiological studies have reported an increase in the incidence over the last 30 years in this population $[1,2,6]$. For instance, in the United States of America (USA), the overall incidence of invasive GBS infection increased between 2008 and 2016, increasing from 8.1 cases to 10.9 cases per 100,000 inhabitants [6]. These infections are often severe, requiring hospitalization and intensive care unit (ICU) management in 94\% and $27 \%$ of cases in the USA, respectively [6].

Skin and soft tissue infections (SSTI) (e.g., erysipelas, cellulitis), isolated bacteremia, osteomyelitis, and urinary tract infections are the most common clinical manifestations of invasive GBS infections. Pneumonia, meningitis, endocarditis, and septic shock are also observed [2, 6-9]. Risk factors for invasive GBS infection in adults include immunosuppression, obesity, diabetes, cancer, and cirrhosis [1, 2, 6-10]. The elderly are particularly at risk of severe GBS infections due to significant comorbidities, disruption of anatomical barriers, and modifications of the immune responses secondary to immunosenecence [11].

Regarding antibiotic susceptibility, GBS remains susceptible to penicillin, the first-line treatment. However, reports of reduced susceptibility to penicillin, associated with mutations in penicillin binding proteins, have been published $[1,7,12$, 13]. Since two decades, increased emergence of resistance to clindamycin and erythromycin is reported worldwide [14] and in Belgium [15].

To date, ten serotypes of GBS, based on specific capsular polysaccharide (CPS) antigens have been described: Ia, Ib, and II to IX. Serotypes Ia, Ib, II, III, and V are the most common serotypes found in most countries [2, 6-9]. Some studies report a recent emergence of serotype IV as a causative agent of adult GBS infections [6, 7, 16]. In addition, it has been reported that some serotypes are more virulent than others and that their distribution varies geographically [6-9].

The objective of this study is to assess the incidence, clinical, microbiological features and outcome of invasive GBS infections presented by non-pregnant adults in three tertiary hospitals of the Brussels-Capital Region from 2005 to 2019.

\section{Material and methods}

\section{Study design}

This is a multicentric retrospective study carried out in 3 university hospitals in Brussels, Belgium, from January 1, 2005, to November 30, 2019: CUB Erasme-a 858-bed hospital, CHU Brugmann - a 853-bed hospital, and CHU SaintPierre - a 582-bed hospital.

\section{Identification of the cases}

All GBS-positive cultures isolated from normally sterile sites collected from patients in the three institutions during the study period were extracted from the respective laboratory information systems. We excluded patients under 18 years of age, women who were pregnant or who delivered within 30 days of the bacterial isolate sample, and also women of childbearing age (estimated age 18-55 years) with unknown pregnancy status. Patients hospitalized less than $24 \mathrm{~h}$ and those who had issued a notice of non-use of their data were also excluded. Superficial skin specimens or specimens from a non-sterile site (e.g., intrauterine device) were not retained. In case of duplicate GBS isolated from the same patient and the same site, the first isolate was retained. When several concomitant invasive infections were identified in the same patient (e.g., osteoarticular infection with cellulitis), only the deepest infection was retained (osteoarticular infection). Polymicrobial invasive infections were also retained. GBS infection was considered recurrent if the patient presented 2 positive cultures at least 30 days apart, and it was considered healthcare-associated if GBS was isolated from specimens collected more than 2 days after hospital admission.

\section{Collection of clinical data}

Study data were collected and managed using REDCap hosted at CHU Saint-Pierre [17].

Clinical data for each patient, including clinical manifestations, sociodemographic data (age, sex, weight, height, ethnicity, addictions), comorbidities, date and length of hospital stay, ICU admission, and mortality were obtained directly from review of the medical records. Comorbidities which were not mentioned in the medical records were considered absent. Patients were classified as residents of long-term care facilities if this was their designated place of residence at the time of initial positive culture for GBS. The body mass index was calculated; obesity was defined as a BMI $\geq 30 \mathrm{~kg} / \mathrm{m}^{2}$. The Charlson Comorbidity Index (CCI) was applied to all patients to categorize patients according to their comorbidities and to estimate life expectancy at 10 years (with a maximum score of 37) [18]. Death was considered related to GBS if it occurred 
during hospitalization for invasive GBS. Cause of death and response to antibiotherapy were not assessed. Definitions of the clinical manifestations of invasive GBS infections can be found in the Electronic Supplementary Material.

\section{GBS culture and identification}

GBS were isolated from sterile sites by culture of the clinical sample on sheep blood agars such as Columbia agar. Before 2010, the identification of GBS was based on micro- and macroscopic examination (Gram staining, beta-hemolysis) and identification of the group B antigen using a rapid agglutination tests. After 2010, suspected colonies were identified using MatrixAssisted Laser Desorption/Ionization Time-of-Flight Mass Spectrometry (MALDI-TOF MS) and the Biotyper database (Bruker Daltonics). Invasive strains were referred to the Belgian National Reference Centre (CHU Liège) for further testing including capsular serotyping and/or genotyping, and isolates were kept stored at $-80^{\circ} \mathrm{C}$ in sterile glycerol-free skimmed milk.

\section{Antimicrobial susceptibility testing}

Routine antimicrobial susceptibility testing (AST) was performed using the disk diffusion technique for the following antibiotics: penicillin, vancomycin, erythromycin, clindamycin, and fluoroquinolones (levofloxacin). In order to categorize the isolate as "susceptible," "intermediate," or "resistant" to the tested antibiotic, zone diameters were interpreted using the CLSI or the EUCAST guidelines, if before or after 2010, respectively. For clindamycin, the detection of inducible resistance was performed by double disk diffusion testing (DD-test) as already recommended in Belgium in 2005 [19]. If a flattening of the zone of inhibition adjacent to the erythromycin disk (D-zone) was observed, clindamycin was considered resistant (inductible MLSB phenotype). Etest was not systematically carried out.

\section{Capsular serotyping}

In Belgium, it is recommended but not mandatory for the laboratories to send blood cultures and CSF isolates to the National Reference Laboratory for serotyping. Serotyping of CPS was performed using the modified Strep-B-Latex method (Strep-B-Latex kit, Statens Serum Institut, Copenhagen, Denmark) based on the agglutination of latex beads that display CPS serotype-specific IgGs. In case of double agglutination for different serotypes, the strains were subcultured and further characterized by serotyping. For some strains, the amount of capsule produced was not sufficient for characterization with an agglutination method; therefore, some isolates were "not typable." Capsular serotyping was also confirmed by genotyping using a multiplex PCR assay for types Ia to VIII [20] and the PCR described by Kong for type IX [21].

\section{Statistical analysis}

Calculation of incidence was based on hospital catchment population and the number of cases observed over the year in consideration. The hospital catchment population was calculated from the hospital's market share of hospital admissions per year as reported by Belgian Federal Public Service Public Health [22] and from the number of inhabitants per municipality for the year concerned based on the distribution of age classes. As these data were not available before 2009, incidences rate were calculated between 2009 and 2018. Rate of antibiotic resistance was compared over time. Descriptive statistics were used to describe population characteristics, clinical symptoms, and risk factors. Frequencies and percentages were used for categorical data, and median and interquartile range (IQR) for continuous data. We analyzed population characteristics and clinical manifestation by age group. Different patient groups were compared using the Fischer exact test for categorical data and the Wilcoxon-Mann-Whitney test for continuous. We performed multivariate analysis using logistic regression to identify mortality risk factors. The risk factors considered for analysis are as follows: age $\geq 65, \mathrm{CCI} \geq 4$, sex, long-term care facilities, and healthcare-associated infection. All $p$ values are bilateral. A value of $p<0.05$ was considered statistically significant. Analyses and graphs were performed using the SAS program (version 9.4; SAS Institute, Cary, NC, USA).

\section{Ethical aspects}

The study was approved by the ethics committees from the three institutions.

\section{Results}

A total of 730 GBS isolates were extracted from the respective laboratory information systems (CUB Erasme $n=312$, CHU Brugmann $n=230$, and CHU Saint-Pierre $n=188$ ). After consulting the medical records and based on the exclusion criteria, 337 cases of invasive GBS infections in non-pregnant adults were identified in the 3 hospitals between 2005 and 2019 (CUB Erasme $n=135$ (40.1\%), CHU Saint-Pierre $n=75$ (22.3\%), CHU Brugmann $n=127$ (37.7\%)) (Fig. 1).

GBS was mainly isolated from blood cultures (205/337; $60.8 \%)$ followed by abscess puncture $(49 / 337 ; 14.5 \%)$, bone biopsy $(46 / 337 ; 13.7 \%)$, abdominal fluid $(20 / 337 ; 6.0 \%)$, joint fluid $(15 / 337 ; 4.5 \%)$, pleural fluid $(2 / 337 ; 0.6 \%)$, and cerebrospinal fluid $(1 / 337 ; 0.3 \%)$.

\section{Sociodemographic features and risk factors}

The characteristics of the patient population are reported in Table 1. Patients were predominantly male, with a median 


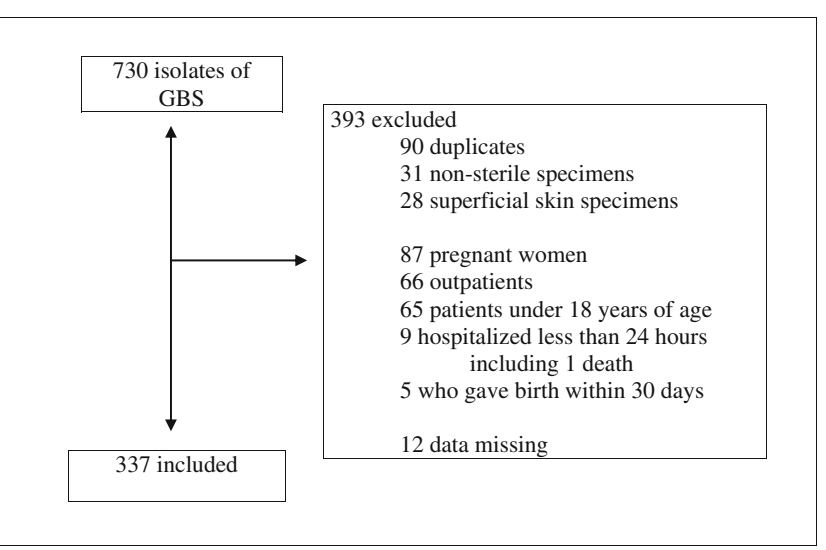

Fig. 1 Data flowchart of invasive GBS infections in Brussels-Capital Region, 2005-2019

age of 62 years. One or more underlying conditions were present in $88.7 \%$ of the patients. Almost one-third of the patients $(95 / 337 ; 28.2 \%)$ had a CCI $\geq 6$ indicating a life expectancy at 10 years of $0 \%$ for these patients. The most common underlying conditions were advanced age ( $47.2 \% \geq 65$ years), diabetes $(36.8 \%)$, obesity $(35.0 \%)$, peripheral vascular disease $(23.2 \%)$, cancer $(21.7 \%)$, and renal disease $(20.8 \%)$ (Table 1$)$. Diabetes and obesity were more common in patients $\geq 65$ years of age than in younger age groups. Recurrent disease was observed in $4.8 \%$ of cases. ICU admission was required in $21.7 \%(73 / 337)$ of the cases and overall mortality was $9.4 \%$.

\section{Incidence of invasive GBS infection}

Between 2009 and 2018, the incidence of invasive GBS for the 3 hospitals significantly increased from 3.7 to 8.2 cases per 100.000 inhabitants $(p=0.04)$ (Fig. 2).

\section{Clinical manifestations}

Isolated bacteremia, osteoarticular infection, SSTI, and abscess were the most frequent manifestations of invasive GBS infection. Of the 15 endocarditis cases, 5 (33.3\%) required heart surgery. Of the 337 cases, 6.5\% developed a septic shock. Patients aged $\geq 65$ years were more likely to have non-focal bacteremia and SSTI as compared with younger patients. In contrast, bone and joint infections, and abscesses, were more common in patients aged 40-64 years (Table 2). Patients with diabetes were more likely to have osteoarticular infection $(36 / 124 ; 29 \%)$, SSTI $(26 / 124 ; 21 \%)$, and bacteremia without focus $(25 / 124 ; 20.2 \%)$ than to have other manifestations. Obese patients were more likely to have SSTI $(19 / 76 ; 25 \%)$ or abscess $(17 / 76 ; 22.4 \%)$ as compared with other manifestations. Cases with recurrent diseases were significantly more likely to manifest osteoarticular infection $(6 / 15 ; 40 \%)$ and to be associated with diabetes $(6 / 15 ; 40 \%)$, obesity $(4 / 15 ; 26.7 \%)$, and peripheral vascular disease $(5 / 15$; $33.3 \%)$.

\section{Mortality risk factors}

The CCI showed that the percentage of death increased markedly with age, from $2.1 \%(2 / 94)$ in those under 50 years to $27.9 \%(17 / 61)$ in those over 80 years. There was no statistical difference in mortality between the three hospitals $(8.3 \%$ CUB Erasme, 9.6\% CHU Saint-Pierre, and 10.4\% CHU Brugmann). Mortality was slightly but significantly higher in men as compared with women $(51.6 \%$ vs. $48.4 \%$; $p=$ $0.03)$. More than half $(17 / 31 ; 54.8 \%)$ of the observed deaths occurred in patients over 80 years old and $20.7 \%(6 / 29)$ occurred in long-term care facility residents. Among the fatal cases, $32.3 \%$ (10/31) were healthcare-associated. The more frequent clinical manifestations among deceased patients were isolated bacteremia $(15 / 31 ; 48.4 \%)$, SSTI $(7 / 31 ; 22.6 \%)$, endocarditis $(4 / 31 ; 12.9 \%)$, intra-abdominal infection $(3 / 31$; $9.7 \%)$, and pneumonia $(2 / 31 ; 6.5 \%)$. The following factors were independently associated with mortality: $\mathrm{CCI} \geq 4$ (OR 9.0; IC 95\% 2.1-34.5), and healthcare-associated infection (OR 6.1; IC 95\% 2.1-17.5) (Table 3).

\section{Antibiotic-susceptibility testing results}

Table 4 describes the results of AST. No penicillin- or vancomycin-resistant strain was identified. Resistance to erythromycin and clindamycin varied over the years but regularly reached peaks of up to more than $20 \%$ resistance. There was no statistically significant difference in antibiotic resistance between the 3 hospitals.

\section{Serotype distribution}

From 2005 to 2019, serotyping was performed on a total of 62 $(18.4 \%)$ collected isolates (Table 5). The available serotypes were mainly determined on isolates from positive blood culture $(n=61)$. One serotype was identified on a CSF culture. Serotypes Ia, Ib, II, III, IV, and V represented $96.8 \%$ of the serotypes in our study. The four main serotypes identified were III (21\%), Ia, II, and V (each 19.4\%), followed by Ib and IV ( $8.1 \%$ for both). Serotypes VII, VIII, and IX were rarely identified.

\section{Discussion}

We performed a retrospective, multicentric study to assess the incidence, clinical, microbiological features and outcome of invasive GBS infections in non-pregnant adults of the Brussels-Capital Region. 
Table 1 Characteristics of non-pregnant adults with invasive GBS infections per age group

\begin{tabular}{|c|c|c|c|c|c|c|}
\hline \multicolumn{2}{|l|}{ Variables } & \multirow{2}{*}{$\begin{array}{l}\text { All } \\
n=337(100 \%)\end{array}$} & \multirow{2}{*}{$\begin{array}{l}18-39 \text { years } \\
n=56(16.6 \%)\end{array}$} & \multirow{2}{*}{$\begin{array}{l}\begin{array}{l}40-64 \text { years } \\
n=122(36.2 \%)\end{array} \\
81(66.4 \%)\end{array}$} & \multirow{2}{*}{$\begin{array}{l}\geq 65 \text { years } \\
n=159(47.2 \%) \\
81(50.9 \%)\end{array}$} & \multirow{2}{*}{$\frac{p \text { value* }{ }^{* 1}}{0.031}$} \\
\hline Sex & Male & & & & & \\
\hline & Female & $141(41.8 \%)$ & $22(39.3 \%)$ & $41(33.6 \%)$ & $78(49.1 \%)$ & 0.031 \\
\hline \multicolumn{2}{|c|}{ Median age (years) } & 62 (IQR 48-95) & 31 (IQR 25-39) & 53 (IQR 48-63) & 77 (IQR 70-95) & $<0.0001$ \\
\hline \multicolumn{2}{|c|}{ Median BMI $\left(\mathrm{kg} / \mathrm{m}^{2}\right)$} & 26 (IQR 22-45) & 25 (IQR 22-44) & 27 (IQR 23-43) & 27 (IQR 22-45) & 0.418 \\
\hline \multirow[t]{3}{*}{ Ethnic group } & $\begin{array}{l}\text { Europe } \\
\text { North Africa }\end{array}$ & $\begin{array}{l}240 / 320(75 \%) \\
50 / 320(15.6 \%)\end{array}$ & $\begin{array}{l}26 / 51(51.0 \%) \\
13 / 51(25.5 \%)\end{array}$ & $\begin{array}{l}84 / 113(74.3 \%) \\
17 / 113(15.0 \%)\end{array}$ & $\begin{array}{l}130 / 156(83.3 \%) \\
20 / 156(12.8 \%)\end{array}$ & \multirow[t]{3}{*}{$<0.0001$} \\
\hline & Sub-Saharan Africa & $24 / 320(7.5 \%)$ & $10 / 51(19.6 \%)$ & $9 / 113(8.0 \%)$ & $5 / 156(3.2 \%)$ & \\
\hline & Others & $6 / 320(1.9 \%)$ & $2 / 51(3.9 \%)$ & $3 / 113(2.7 \%)$ & $1 / 156(0.6 \%)$ & \\
\hline \multicolumn{2}{|c|}{ Median length of stay (days) } & 12 & 7 & 11.5 & 14 & 0.005 \\
\hline \multicolumn{2}{|c|}{ Healthcare-associated } & $44 / 327(13.5 \%)$ & $3 / 54(5.6 \%)$ & $17 / 118(14.4 \%)$ & $24 / 155(15.5 \%)$ & 0.171 \\
\hline \multicolumn{2}{|c|}{ Recurrent disease } & $15 / 314(4.8 \%)$ & $3 / 51(5.9 \%)$ & $7 / 115(6.1 \%)$ & $5 / 148(3.4 \%)$ & 0.547 \\
\hline \multicolumn{2}{|c|}{ Long-term care facilities resident } & $21 / 322(6.5 \%)$ & 0 & 0 & $21 / 151(13.9 \%)$ & $<0.0001$ \\
\hline \multicolumn{2}{|l|}{ ICU } & $73 / 337(21.7 \%)$ & $12(21.4 \%)$ & $28(23.0 \%)$ & $33(20.8 \%)$ & 0.916 \\
\hline \multicolumn{2}{|l|}{ Death } & $31 / 330(9.4 \%)$ & $3 / 56(5.4 \%)$ & $4 / 120(3.3 \%)$ & $24 / 154(15.6 \%)$ & 0.001 \\
\hline \multicolumn{7}{|c|}{ Underlying condition } \\
\hline \multicolumn{2}{|c|}{$\geq 1$ conditions } & $299(88.7 \%)$ & $33(58.9 \%)$ & $105(86.1 \%)$ & $159(100 \%)$ & $<0.0001$ \\
\hline \multicolumn{2}{|l|}{ Diabetes } & $124(36.8 \%)$ & $12(21.4 \%)$ & $46(37.7 \%)$ & $66(41.5 \%)$ & 0.050 \\
\hline \multicolumn{2}{|l|}{ Obesity } & $76 / 217(35.0 \%)$ & $8 / 30(26.7 \%)$ & $32 / 89(36.0 \%)$ & $36 / 98(36.7 \%)$ & 0.844 \\
\hline \multicolumn{2}{|l|}{ Cancer* $^{2}$} & $77(21.7 \%)$ & $3(5.4 \%)$ & $20(16.4 \%)$ & $50(31.5 \%)$ & 0.004 \\
\hline \multicolumn{2}{|l|}{ Renal disease } & $70(20.8 \%)$ & $9(16.1 \%)$ & $20(16.4 \%)$ & $41(25.8 \%)$ & 0.100 \\
\hline \multicolumn{2}{|c|}{ Neurologic disease ${ }^{* 3}$} & $47(14.0 \%)$ & $2(3.6 \%)$ & $8(6.6 \%)$ & $37(23.3 \%)$ & 0.028 \\
\hline \multicolumn{2}{|c|}{ Heart failure disease } & $67(19.9 \%)$ & $1(1.8 \%)$ & $16(13.1 \%)$ & $50(31.4 \%)$ & 0.031 \\
\hline \multicolumn{2}{|c|}{ Chronic obstructive pulmonary disease } & $45(13.4 \%)$ & $3(5.4 \%)$ & $13(10.7 \%)$ & $29(18.2 \%)$ & 0.028 \\
\hline \multicolumn{2}{|c|}{ Current smoker } & $90 / 305(29.5 \%)$ & $14 / 50(28 \%)$ & $48 / 115(41.7 \%)$ & $28 / 140(20 \%)$ & 0.001 \\
\hline \multicolumn{2}{|l|}{ Liver disease } & $37(11.0 \%)$ & $5(8.9 \%)$ & $21(17.2 \%)$ & $11(6.9 \%)$ & 0.058 \\
\hline \multicolumn{2}{|c|}{ Peripheral vascular disease } & $78(23.2 \%)$ & $6(10.7 \%)$ & $26(21.3 \%)$ & $46(28.9 \%)$ & 0.018 \\
\hline \multicolumn{2}{|l|}{ IVDU } & $9 / 303(3.0 \%)$ & $4 / 50(8 \%)$ & $5 / 113(4.4 \%)$ & 0 & 0.009 \\
\hline \multicolumn{2}{|l|}{ Alcohol } & $69 / 306(22.6 \%)$ & $7 / 50(14 \%)$ & $41 / 115(35.7 \%)$ & $21 / 141(14.9 \%)$ & $<0.0001$ \\
\hline
\end{tabular}

Data are expressed as numbers and percentages for categorical data and median (IQR) for continuous data. Denominators are smaller for ethnic group, obesity, addictions, healthcare-associated, recurrent disease, ICU, deaths, and long-term care facility residents because we did not have all data in medical records for all 337 patients

$B M I$, body mass index; $I C U$, intensive care unit; $I V D U$, intravenous drug use

${ }^{* 1}$ For the comparison of results among the groups of cases in patients aged $18-39$ years, $40-64$ years, and $\geq 65$ years. $p<0.05$ was considered statistically significant

* ${ }^{2}$ Cancer includes Hodgkin and non-Hodgkin lymphoma, leukemia, and solid organ tumor

$*^{3}$ Neurologic disease includes dementia or stroke

Over $80 \%$ of the clinical manifestations of invasive GBS infection were bacteremia without focus, osteoarticular infection, SSTI, and abscesses. Over $80 \%$ of these patients presented an underlying condition, diabetes and obesity being the most frequent. These infections were severe, as almost one quarter of patients were admitted to the ICU and an almost $10 \%$ mortality rate was observed. Over $50 \%$ of deaths occurred in patients over 80 years old. In our study, the risk factors associated with higher mortality were a CCI $\geq 4$, and healthcare-associated infections. Our results are similar to those reported in the literature as global in-hospital mortality for non-pregnant adults is estimated to range from 3 to $23.7 \%$ worldwide $[1,2,16]$. Other factors previously associated with mortality are cancer, septic shock, peritonitis, endocarditis, and meningitis $[8,23]$.

During the study period, GBS strains remained fully susceptible to penicillin and vancomycin. Resistance to erythromycin and clindamycin varied over the years but regularly reached peaks of $20-30 \%$, in accordance with data reported by the GBS National Center in 2016 [15]. Clindamycin 


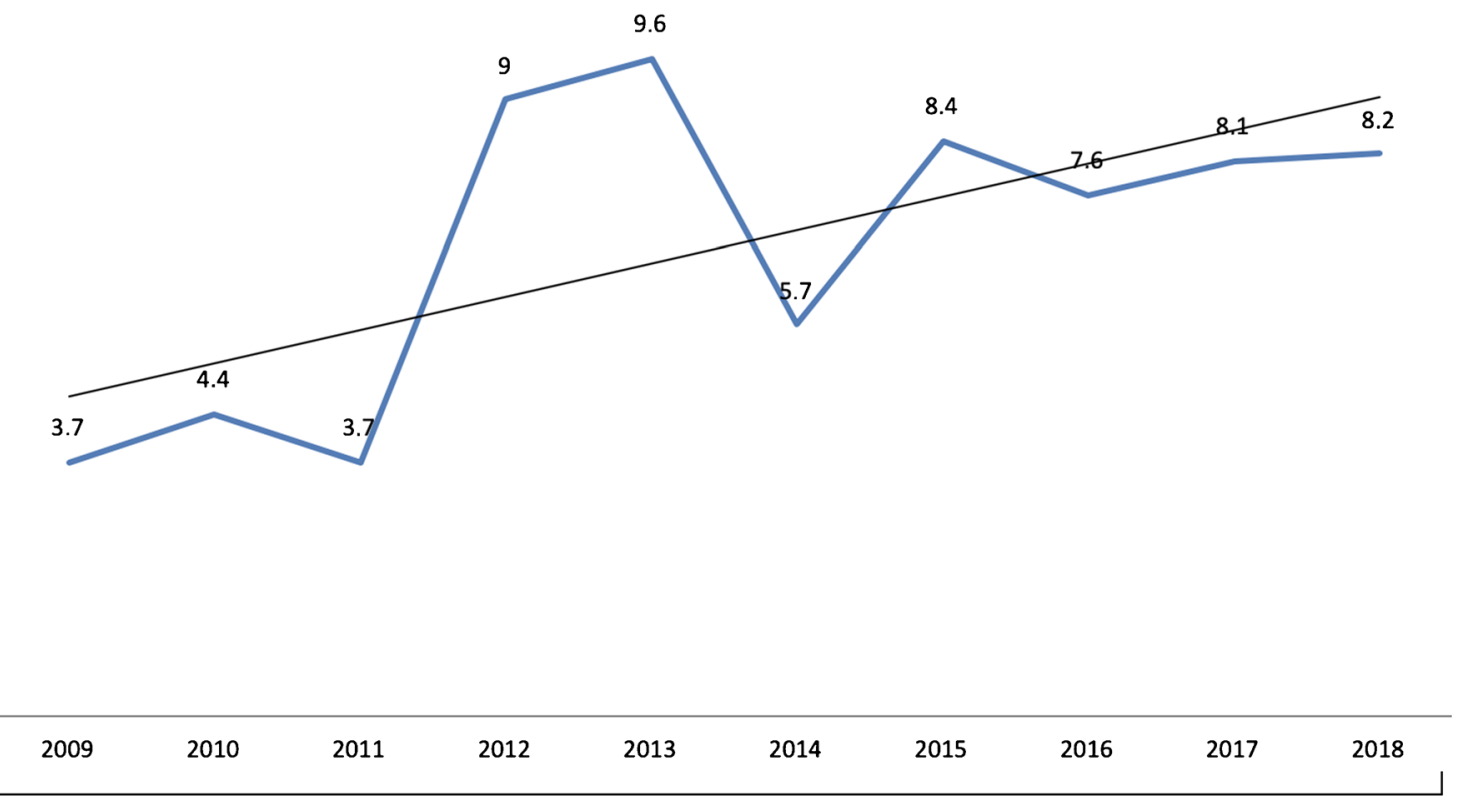

Fig. 2 Incidence per 100.000 person-years of invasive GBS disease among non-pregnant adults from 2009 to 2018 in the three Brussels hospitals

resistance is worrisome as it is used as a second-line agent in case of allergy to penicillin [9, 14, 24].

Since the 1990s, serotype V has emerged in the USA and became the most common serotype causing invasive GBS disease in non-pregnant adults [25]. Later, other serotypes such as Ia, Ib, II, III, and IV were also recognized worldwide as common serotypes [25]. However, the distribution of serotypes varies geographically over time: an increase in the incidence of serotypes Ib, II, and IV in the USA [6], serotypes IV and V in Iceland [7], and serotype III in France [9]. In a 1-year survey in Belgium, during the year 2018, the most prevalent serotypes were Ia $(25.1 \%), \mathrm{V}(23 \%)$, and III (19.6\%) coming

Table 2 Clinical manifestations of non-pregnant adults with invasive GBS infections

\begin{tabular}{|c|c|c|c|c|c|}
\hline & $\begin{array}{l}\text { All } \\
n=337 \\
(100 \%)\end{array}$ & $\begin{array}{l}18-39 \text { years } \\
n=56 \\
(16.6 \%)\end{array}$ & $\begin{array}{l}40-64 \text { years } \\
n=122 \\
(36.2 \%)\end{array}$ & $\begin{array}{l}\geq 65 \text { years } \\
n=159 \\
(47.2 \%)\end{array}$ & $p$ value ${ }^{* 1}$ \\
\hline Bacteremia without focus & $74(22.0 \%)$ & $7(12.5 \%)$ & $22(18 \%)$ & $45(28.3 \%)$ & 0.021 \\
\hline Osteoarticular infection & $72(21.4 \%)$ & $11(19.6 \%)$ & $34(27.9 \%)$ & $27(17 \%)$ & 0.088 \\
\hline SSTI & $62(18.4 \%)$ & $7(12.5 \%)$ & $10(8.2 \%)$ & $45(28.3 \%)$ & $<0.0001$ \\
\hline Soft tissue abscess & $47(13.9 \%)$ & $15(26.8 \%)$ & $25(20.5 \%)$ & $7(4.4 \%)$ & $<0.0001$ \\
\hline Intra-abdominal infection & $25(7.4 \%)$ & $4(7.1 \%)$ & $14(11.5 \%)$ & $7(4.4 \%)$ & 0.075 \\
\hline Endocarditis & $15(4.5 \%)$ & $2(3.6 \%)$ & $5(4.1 \%)$ & $8(5 \%)$ & 0.939 \\
\hline Pneumonia $*^{2}$ & $13(3.9 \%)$ & $2(3.6 \%)$ & $4(3.3 \%)$ & $7(4.4 \%)$ & 0.929 \\
\hline Invasive urinary tract infection & $12(3.6 \%)$ & $2(3.6 \%)$ & $2(1.6 \%)$ & $8(5 \%)$ & 0.408 \\
\hline Others $*^{3}$ & $12(3.6 \%)$ & $5(8.9 \%)$ & $4(3.3 \%)$ & $3(1.9 \%)$ & 0.417 \\
\hline Meningitidis & $5(1.5 \%)$ & $1(1.79 \%)$ & $2(1.64 \%)$ & $2(1.26 \%)$ & 1.00 \\
\hline Septic shock-associated & $22 / 337(6.5 \%)$ & $3(5.4 \%)$ & $6(4.9 \%)$ & $13(8.2 \%)$ & 0.558 \\
\hline
\end{tabular}

Definitions of the clinical manifestations are found in the Electronic Supplementary Material

SSTI, skin and soft tissue infection

$*^{1}$ For the comparison of results among the groups of cases in patients aged 18-39 years, 40-64 years, and $\geq 65$ years

$*^{2}$ Includes empyema

$*^{3}$ Other clinical syndrome included pelvic infection $(n=2)$, post myomectomy sepsis $(n=2)$, sinusitis $(n=1)$ and infection of an indwelling or implanted medical device $(n=7)$ 
Table 3 Mortality risk factors in hospitalized patients with invasive GBS infection

\begin{tabular}{|c|c|c|c|c|c|c|c|}
\hline & \multirow{2}{*}{$\begin{array}{l}\text { Death } \\
(n=31) \\
(9.4 \%)\end{array}$} & \multirow{2}{*}{$\begin{array}{l}\text { Alive } \\
(n=299) \\
(90.6 \%)\end{array}$} & \multirow[t]{2}{*}{$p$ value } & \multicolumn{2}{|c|}{ Univariate analysis } & \multicolumn{2}{|c|}{ Multivariate analysis } \\
\hline & & & & OR & IC $95 \%$ & OR & IC $95 \%$ \\
\hline Age $\geq 65$ & $24(77.4 \%)$ & $127(42.5 \%)$ & $<0.001$ & 4.6 & $1.9-11.5$ & 1.9 & $0.5-7.4$ \\
\hline $\mathrm{CCI} \geq 4$ & $26(83.9 \%)$ & $138(46.2 \%)$ & $<0.001$ & 6.1 & $2.2-20.7$ & 9.0 & $2.1-34.5$ \\
\hline Sex: male & $16(51.6 \%)$ & $178(59.5 \%)$ & $<0.394$ & 0.7 & $0.3-1.6$ & & \\
\hline Long-term care facilities ${ }^{* 1}$ & $6 / 29(20.7 \%)$ & $15 / 286(5.2 \%)$ & $<0.015$ & 4.7 & $1.3-14.3$ & 2.9 & $0.8-10.0$ \\
\hline Healthcare-associated $*^{2}$ & $10(32.3 \%)$ & $33 / 293(11.3 \%)$ & 0.002 & 4.6 & $1.7-11.7$ & 6.1 & $2.1-17.5$ \\
\hline
\end{tabular}

Data are expressed as numbers and percentages. A multivariate analysis using logistic regression was performed to identify mortality risk factors. Denominators are lower than $n$ when there was a lack of data in the medical records

CCI, Charlson Comorbidity Index

$*^{1}$ Denominators are 29 for death patients and 286 for alive patients

$*^{2}$ Denominators are 293 for alive patients

from 143 GBS-positive samples from invasive disease among non-pregnant adults [26]. In our study, serotypes Ia, Ib, II, III, IV, and V accounted for over $95 \%$ of the available serotypes.

The incidence of invasive GBS infections in non-pregnant adults in the Brussels-Capital Region almost tripled between 2009 and $2018(p=0.04)$. The increase in the incidence of invasive GBS infection in non-pregnant adults is observed in many countries and is associated with an increase in mortality over time $[1,2,6,9,25]$. The aging of the population but also the increasing prevalence of obesity and diabetes could contribute to this increase in invasive GBS infections [27, 28]. In England, the incidence tripled between 1991 and 2016 and was mainly attributable to the elderly [10]. Recent studies

Table 4 Antibioticsusceptibility test results for GBS-invasive strains

\begin{tabular}{lll}
\hline & & $n(\%)$ \\
\hline Penicillin & S & $335 / 335(100)$ \\
& I & $0 / 335(0)$ \\
& R & $0 / 335(0)$ \\
Erythromycin & S & $219 / 334(65.6)$ \\
& I & $22(6.6)$ \\
& R & $93(27.8)$ \\
Clindamycin & S & $251 / 332(75.6)$ \\
& I & $9(2.7)$ \\
& R & $72(21.7)$ \\
Vancomycin & S & $334 / 334(100)$ \\
& I & 0 \\
& R & 0 \\
Levofloxacin & S & $89 / 106(84.0)$ \\
& I & $10 / 106(9.4)$ \\
& R & $7 / 106(6.6)$ \\
& NA & $224 / 337(66.5)$ \\
\hline
\end{tabular}

$S$, sensitive; $I$, intermediate; $R$, resistant; $N A$, not available

performed in the USA [6, 29] and France [30] reported incidences of GBS-invasive disease that were higher than that of invasive pneumococcal diseases (IPD) in adults. In Belgium, the incidence for IPD in adults in 2018 was 17 cases per 100,000 inhabitants which is higher than the incidence of invasive GBS infections observed in our study. Various factors could explain these differences. In Belgium, there is a good surveillance of IPD, covering about $85-90 \%$ of the Belgian population, which is different compared with other countries where data is collected only from hospitals/regions and then extrapolated to the whole country. Also, vaccine coverage against Streptococcus pneumoniae is high in children but low in older persons and at risk patients. (Stefanie Desmet, personal communication).

We found a high proportion of healthcare-associated infections. We used an arbitrary definition usually used for other healthcare-associated infections (> $48 \mathrm{~h}$ ) [31]. Clusters of

Table 5 Serotype distribution of 62 isolates of GBS-invasive isolates from 2005 to 2019

\begin{tabular}{ll}
\hline Serotypes & $\begin{array}{l}n=62 \\
(100 \%)\end{array}$ \\
\hline Ia & $12(19.4)$ \\
Ib & $5(8.1)$ \\
II & $12(19.4)$ \\
III & $13(21)$ \\
IV & $5(8.1)$ \\
V & $12(19.4)$ \\
VI & 0 \\
VII & 0 \\
VIII & $1(1.6)$ \\
IX & $1(1.6)$ \\
\hline
\end{tabular}

Data are expressed as numbers and percentages. Data are limited to cases with available isolates: isolates were available for 62 of 337 cases from the 3 hospitals 
invasive GBS infections linked to nosocomial transmission have been reported in neonatal intensive care units [32]. The evidence for nosocomial transmission of invasive GBS infection is however much weaker in hospitalized adults [32]. Healthcare-associated GBS infections could be related to delay in acquisition of the sample or secondary to intra-hospital procedures such as surgery. We found an association between healthcare-associated infections and mortality. This observation warrants further prospective studies on healthcareassociated invasive GBS.

Invasive GBS infection in adults is responsible for a significant health burden. Vaccination against GBS may offer a solution to diminish morbidity and mortality. In recent years, significant progress has been made in vaccine development, primarily to prevent neonatal diseases. Administered during pregnancy, vaccines aim to protect newborns by transplacental transfer of specific antibodies against these polysaccharides [33]. A hexavalent polysaccharide (GBS6) conjugate vaccine, containing the 6 serotypes responsible for $98 \%$ of invasive infections in neonates and adults (Ia, Ib, II, III, IV, and V), is being evaluated in healthy adults after encouraging protective effects have been demonstrated in animals [34]. Although there is no clinical evidence that antibodies can prevent GBS infection in adults, healthy and infected older adults are able to produce anti-GBS CPS antibodies. This has been shown both in vaccine trials and following GBS infection [34]. The development of a GBS6 vaccine as a new preventive strategy could potentially prevent these infections in at-risk adults as $97 \%$ of the serotypes identified in our study are included in the GBS6 vaccine.

\section{Limitations}

Our study has several limitations. First, this is a retrospective study, but this is the first study to describe GBS-invasive infection in non-pregnant adults in the Brussels-Capital Region. Second, the focus of this study was limited to invasive GBS disease and invasive samples. GBS also causes many noninvasive diseases, including SSTI, the vast majority of which do not lead to documented bacteremia. In the present study, only SSTI infections with concomittant bacteremia or skin abscesses requiring drainage were included. The overall burden of GBSinvasive infections in adults is likely to be much higher [6]. Third, we excluded patients hospitalized less than $24 \mathrm{~h}$ due to lack of data, but this did not change data on mortality because only one of the patients excluded from the study died. Fourth, only $18.4 \%$ of strains were submitted to serotyping, so we were not able to assess the incidence variations of specific serotypes.

\section{Conclusions}

In the Brussels-Capital Region, similarly as reported in several other countries, invasive GBS disease in non-pregnant adults represents an increasing burden, particularly among older persons and patients with chronic diseases, such as obesity and diabetes. GBS also causes many non-invasive diseases so the overall burden in adults is likely to be much higher. Ongoing monitoring of serotype distribution and antibiotic resistance is warranted. Reducing risk factors through hygienic-dietary rules and maintaining skin integrity may help for the prevention of invasive GBS infections. The development of a GBS6 vaccine as a new preventive strategy could also prevent these infections in at-risk adults. Future studies are needed to assess the potentially positive impact of this vaccine on invasive GBS infections.

Funding N.D. is a post-doctorate Clinical Master Specialist of the FRSFNRS. No specific funding was used for this study.

\section{Compliance with ethical standards}

Conflict of interest Dr Dauby has received a travel grant from Pfizer (outside of the submitted work).

Ethical approval The study was approved by the three institutions' ethics committee.

Informed consent Informed consent is not required because of the retrospective design of this study.

\section{References}

1. Pimentel BAS, Martins CAS, Mendonça JC, Miranda PSD, Sanches GF, Mattos-Guaraldi AL et al (2016) Streptococcus agalactiae infection in cancer patients: a five-year study. Eur J Clin Microbiol Infect Dis 35:927-933. https://doi.org/10.1007/ s10096-016-2617-9

2. Barshak MB (2019) Group B Streptococcus, an A-list pathogen in nonpregnant adults. JAMA Intern Med 179:488. https://doi.org/10. 1001/jamainternmed.2018.7296

3. Russell NJ, Seale AC, O'Driscoll M, O'Sullivan C, Bianchi-Jassir F, Gonzalez-Guarin J et al (2017) Maternal colonization with group B streptococcus and serotype distribution worldwide: systematic review and meta-analyses. Clin Infect Dis 65:S100-S111. https:// doi.org/10.1093/cid/cix658

4. Hasperhoven G, Al-Nasiry S, Bekker V, Villamor E, Kramer B (2020) Universal screening versus risk-based protocols for antibiotic prophylaxis during childbirth to prevent early-onset group B streptococcal disease: a systematic review and meta-analysis. BJOG Int J Obstet Gynaecol 127:680-691. https://doi.org/10. 1111/1471-0528.16085

5. Rantz LA (1940) Suppurative arthritis due to a hemolytic streptococcus of the lancefield group B: a case report. Ann Intern Med 1(13):1744. https://doi.org/10.7326/0003-4819-13-9-1744

6. Francois Watkins LK, McGee L, Schrag SJ, Beall B, Jain JH, Pondo T et al (2019) Epidemiology of invasive group B Streptococcal infections among nonpregnant adults in the United States, 2008-2016. JAMA Intern Med 179:479. https://doi.org/10. 1001/jamainternmed.2018.7269

7. Björnsdóttir ES, Martins ER, Erlendsdóttir H, Haraldsson G, MeloCristino J, Kristinsson KG et al (2016) Changing epidemiology of group B streptococcal infections among adults in Iceland: 1975- 
2014. Clin Microbiol Infect 22:379.e9-379.e16. https://doi.org/10. 1016/j.cmi.2015.11.020

8. Martins ER, Melo-Cristino J, Ramirez M (2012) The Portuguese group for the study of Streptococcal infections. Dominance of serotype Ia among group B streptococci causing invasive infections in nonpregnant adults in Portugal. J Clin Microbiol 50:1219-1227. https://doi.org/10.1128/JCM.05488-11

9. Tazi A, Morand PC, Réglier-Poupet H, Dmytruk N, Billoët A, Antona D et al (2011) Invasive group B streptococcal infections in adults, France (2007-2010). Clin Microbiol Infect 17:15871589. https://doi.org/10.1111/j.1469-0691.2011.03628.x

10. Collin SM, Shetty N, Lamagni T (2020) Invasive group B streptococcus infections in adults, England, 2015-2016. Emerg Infect Dis 26:1174-1181. https://doi.org/10.3201/eid2606.191141

11. High KP, Edwards MS, Baker CJ (2005) Group B streptococcal infections in elderly adults. Clin Infect Dis 41:839-847. https://doi. org/10.1086/432804

12. Kimura K, Suzuki S, Wachino J, Kurokawa H, Yamane K, Shibata $\mathrm{N}$ et al (2008) First Molecular characterization of group B streptococci with reduced penicillin susceptibility. Antimicrob Agents Chemother 52:2890-2897. https://doi.org/10.1128/AAC.00185-08

13. McGee L, Chochua S, Li Z, Mathis S, Rivers J, Metcalf B et al (2020) Multistate, population-based distributions of candidate vaccine targets, clonal complexes, and resistance features of invasive group B streptococci within the United States, 2015-2017. Clin Infect Dis 15:ciaa151. https://doi.org/10.1093/cid/ciaa151

14. Castor ML, Whitney CG, Como-Sabetti K, Facklam RR, Ferrieri P, Bartkus JM et al (2008) Antibiotic resistance patterns in invasive group B streptococcal isolates. Infect Dis Obstet Gynecol 2008:1-5. https://doi.org/10.1155/2008/727505

15. Sacheli R, Melin P (2016) Rapport d'activités du Centre National de Référence du Streptococcus agalactiae

16. Buurman ET, Timofeyeva Y, Gu J, Kim J, Kodali S, Liu Y et al (2019) A Novel hexavalent capsular polysaccharide conjugate vaccine (GBS6) for the prevention of neonatal group B streptococcal infections by maternal immunization. J Infect Dis 220:105-115. https://doi.org/10.1093/infdis/jiz062

17. Harris PA, Taylor R, Thielke R, Payne J, Gonzalez N, Conde JG (2009) Research electronic data capture (REDCap) - A metadatadriven methodology and workflow process for providing translational research informatics support. J Biomed Inform 42:377-381. https://doi.org/10.1016/j.jbi.2008.08.010

18. Charlson M, Szatrowski TP, Peterson J, Gold J (1994) Validation of a combined comorbidity index. J Clin Epidemiol 47:1245-1251. https://doi.org/10.1016/0895-4356(94)90129-5

19. Melin, P. Evaluation externe de la qualité des analyses en biologie clinique. Rapport de microbiologie enquête 02/2005. Partim Streptococcus agalactiae [Internet]. 2005 [cited 2020 7]; doi: https://www.wiv-isp.be/QML/activities/external_quality/rapports/_ down/microbiologie/2005/05-2F-MICROBIO.pdf

20. Poyart C, Tazi A, Reglier-Poupet H, Billoet A, Tavares N, Raymond J et al (2007) Multiplex PCR assay for rapid and accurate capsular typing of group B streptococci. J Clin Microbiol 45:19851988. https://doi.org/10.1128/JCM.00159-07

21. Kong F, Lambertsen LM, Slotved H-C, Ko D, Wang H, Gilbert GL (2008) Use of phenotypic and molecular serotype identification methods to characterize previously nonserotypeable group B streptococci. J Clin Microbiol 46:2745-2750. https://doi.org/10.1128/ JCM.00189-08
22. RHM: Parts de marché des hôpitaux par commune de résidence des patients et classe d'âge [Internet]. [cited 2020 12];doi: https:/www. health.belgium.be/fr/rhm-parts-de-marche-des-hopitaux-parcommune-de-residence-des-patients-et-classe-dage

23. Jump RLP, Wilson BM, Baechle D, Briggs JM, Banks RE, Song S et al (2019) Risk factors and mortality rates associated with invasive group B Streptococcus infections among patients in the US Veterans Health Administration. JAMA Netw Open 27(2): e1918324. https://doi.org/10.1001/jamanetworkopen.2019.18324

24. Lamagni TL, Keshishian C, Efstratiou A, Guy R, Henderson KL, Broughton K et al (2013) Emerging trends in the epidemiology of invasive group B streptococcal disease in England and Wales, 1991-2010. Clin Infect Dis 57:682-688. https://doi.org/10.1093/ $\mathrm{cid} / \mathrm{cit} 337$

25. Skoff TH, Farley MM, Petit S, Craig AS, Schaffner W, Gershman K et al (2009) Increasing burden of invasive group B streptococcal disease in nonpregnant adults, 1990-2007. Clin Infect Dis 49:85-92. https://doi.org/10.1086/599369

26. Sacheli R, Meex C, Melin P, Descy J, Huynen P, Hayette M-P. Surveillance of group B streptococcus (GBS) strains isolated from invasive diseases among adults in Belgium: Bacteriological and clinical characteristics. [Internet]. 2018 [cited 2020 7];doi: http:// hdl.handle.net $/ 2268 / 223202$

27. Healthy Belgium. Obesity prevalence in Belgium [Internet]. [cited 2020 14];doi: https://www.belgiqueenbonnesante.be/fr/etat-desante/determinants-de-sante/statut-ponderal

28. Healthy Belgium. Diabetes prevalence in Belgium [Internet]. [cited 2020 14]; https://www.healthybelgium.be/en/health-status/noncommunicable-diseases/diabetes

29. Centers for Disease Control and Prevention. 2016. Active bacterial core surveillance report, emerging infections program network, Streptococcus pneumoniae, 2016. 2018 20; https://www.cdc.gov/ abcs/reports-findings/survreports/spneu16.pdf

30. Santé Publique France. Bilan annuel 2018: Impact de la vaccination par le vaccin pneumococcique conjugué 13-valent (VPC13) sur l'incidence des infections invasives à pneumocoques. Données du réseau Epibac et du CNR des pneumocoques (réseau CNRP-ORP) [Internet]. [cited 2020 12]; https://www.santepubliquefrance.fr/ maladies-et-traumatismes/maladies-et-infections-respiratoires/ infections-a-pneumocoque/donnees/\#tabs

31. Cardoso T, Almeida M, Friedman ND, Aragão I, Costa-Pereira A, Sarmento AE et al (2014) Classification of healthcare-associated infection: a systematic review 10 years after the first proposal. BMC Med 12:40. https://doi.org/10.1186/1741-7015-12-40

32. Collin SM, Lamb P, Jauneikaite E, Le Doare K, Creti R, Berardi A et al (2019) Hospital clusters of invasive group B streptococcal disease: a systematic review. J Infect 79:521-527. https://doi.org/ 10.1016/j.jinf.2019.11.008

33. Heath PT, Culley FJ, Jones CE, Kampmann B, Le Doare K, Nunes MC et al (2017) Group B streptococcus and respiratory syncytial virus immunisation during pregnancy: a landscape analysis. Lancet Infect Dis 17:e223-e234. https://doi.org/10.1016/S1473-3099(17) 30232-3

34. Dauby N (2019) Vaccination for the prevention of group B Streptococcus infection in nonpregnant adults. JAMA Intern Med 179:998. https://doi.org/10.1001/jamainternmed.2019.1590

Publisher's note Springer Nature remains neutral with regard to jurisdictional claims in published maps and institutional affiliations. 